\title{
Planned and unplanned deliveries at home: implications of a changing ratio
}

\author{
J F MURPHY, MARJORIE DAUNCEY, O P GRAY, I CHALMERS
}

\begin{abstract}
The observation that perinatal mortality among babies delivered at home has tended to increase beyond that among babies delivered in consultant obstetric units has caused alarm and prompted recommendations that delivery at home should be further phased out. With data derived from the Cardiff Births Survey the possibility was investigated that this trend might reflect a changing ratio of planned to unplanned domiciliary births. At the beginning of the 1970 s deliveries at home that were planned to be so outnumbered those that were not by nearly five to one. By 1979 unplanned deliveries at home outnumbered planned deliveries. The characteristics of the mothers, the health care they received, and the outcome of delivery differed strikingly between planned and unplanned deliveries at home.

It is concluded, firstly, that every year the maternity services must try to meet the various needs of about 2000 women in England and Wales who give birth at home without planning to do so; and, secondly, that the heterogeneity of births at home and in hospital will continue to obstruct the search for unbiased estimates of the risks attributable to delivery in specialist obstetric units, general practitioner units, and at home.
\end{abstract}

Welsh National School of Medicine, Cardiff CF4 4XN

J F MURPHY, MRCP, DCH, senior registrar, department of child health

M DAUNCEY, BA, research officer, department of medical statistics

O P GRAY, FRCP, DCH, professor of child health, department of child health

National Perinatal Epidemiology Unit, Radcliffe Infirmary, Oxford OX2 6HE

I CHALMERS, MRCOG, DCH, director of unit

Correspondence to: $\mathrm{Mr}$ I Chalmers.

\section{Introduction}

Several attempts have been made to estimate the relative risks of perinatal death associated with delivery in specialist obstetric units, general practitioner units, and at home. These attempts have been confounded by biases resulting from the complex processes of selection that lead women to deliver in these different places.

In 1975 it became possible to derive figures for perinatal mortality by place of delivery from the linked file of registrations of infant births and deaths held by the Office of Population Censuses and Surveys. An analysis of these data showed that, during 1975-7, perinatal mortality increased among babies delivered at home. ${ }^{1}$ This finding was noted by the social services committee of the House of Commons, which expressed particular concern that perinatal mortality among babies delivered at home was not only increasing but was actually higher than that among babies delivered in hospitals with specialist obstetric units.

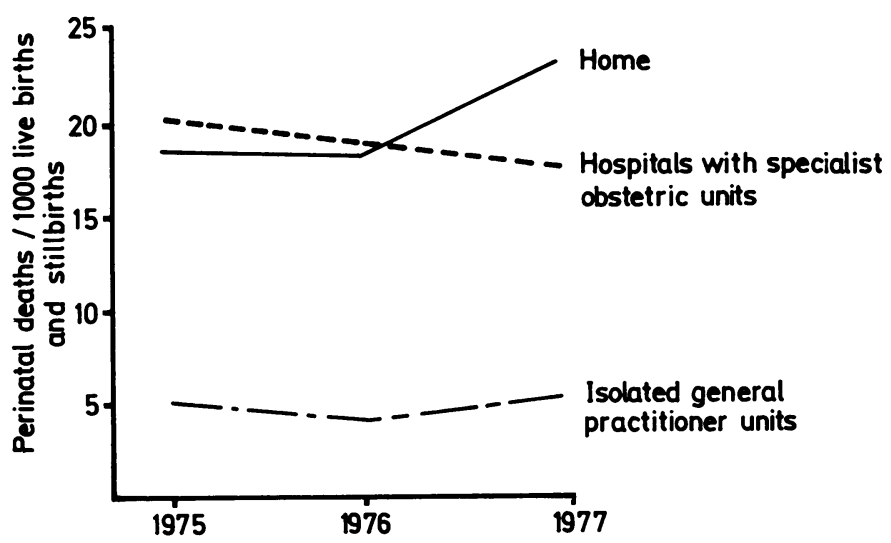

Perinatal mortality according to place of delivery in England and Wales, 1975-7. 
The committee noted that women who gave birth at home included "a proportion of mothers at high risk who had deliberately eschewed hospital care," but it made no reference to deliveries at home that were genuinely not planned and said that "the available data increased [its] concern about the safety for any mother, of home delivery." 2 It went on to recommend that delivery at home be further phased out. ${ }^{2}$ In its reply to the committee's report the government stated that, "Women should be encouraged to have their babies in a hospital offering the range of obstetric, paediatric, and supporting services necessary to cope with any emergencies. Where, however, a mother wishes to have a home confinement, despite the medical arguments against it, health authorities are expected to provide a domiciliary confinement service that is as safe as circumstances permit.", 3

Comments on these recommendations emphasised the importance of considering separately two broad categories of women delivering at home ${ }^{4-6}$ : one category consists of women whom all concerned intend should deliver at home; the other consists of women whose deliveries at home are not planned and includes not only those women who have "deliberately eschewed hospital care" but also women (often schoolgirls) who have made no arrangements for delivery and others whose intentions to deliver in hospital are overtaken by unpremeditated, emergency deliveries at home. As Tew observed, because there is a considerable difference in perinatal mortality between planned and unplanned deliveries at home, any change over time in their relative representation among births at home would be expected to influence trends in overall mortality among babies born at home. ${ }^{7}$

In 1982 Campbell et al in a more detailed analysis of the available national statistics, ${ }^{8}$ confirmed Tew's observations that considerable heterogeneity exists among women delivering at home and that this is reflected in wide variations in perinatal mortality within the population giving birth at home. ${ }^{7}$ In particular, the rise in mortality among babies delivered at home between 1975 and 1977 was shown to have coincided with an increase in the proportions both of births to teenagers and of illegitimate births (which are at greater than average risk of death) among births that had occurred at home. Campbell et al suggested that this probably reflected a change in the ratio of planned to unplanned births at home and that this might have accounted for the overall rise in the observed perinatal mortality that had alarmed the social services committee.

For the present report we used data available through the Cardiff Births Survey ${ }^{9}$ to examine trends in the ratio of planned to unplanned domiciliary births among women resident in Cardiff, Barry, and Penarth during the 1970s.

\section{Subjects and methods}

Using the Cardiff Births Survey, ${ }^{9}$ we studied 44048 women resident in Cardiff, Barry, and Penarth who gave birth between the beginning of 1970 and the end of 1979. During this period 359 women planned to deliver at home, but these plans were changed before the onset of labour in $44(12.3 \%)$. The change from home to hospital booking was prompted by obstetric complications in 18 women, medical complications in six, fetal problems in nine, and a re-evaluation of the wisdom of the initial plans in 11. Of the 315 women who, at the onset of labour, intended to deliver at home, eight $(2.5 \%)$ were transferred to hospital during labour. Transfer was prompted by prolonged labour in three, fetal distress in two, intrapartum haemorrhage in two, and preterm labour in one. Thus $307(85 \%)$ of the 359 women who had originally intended to give birth at home actually did so. In addition, 159 women gave birth at home without having planned to do so. One hundred and twenty nine of them had planned to deliver in hospital, and 30 had not received any antenatal care and thus had not been booked to deliver either at home or in hospital.

Altogether, therefore, 466 women resident in Cardiff, Barry, and Penarth gave birth at home during the decade 1970-9. The Cardiff Births Survey was used to document trends in the incidence of the three categories of delivery at home described above and to compare the mothers and infants in each category.

\section{Results}

The overall incidence of births at home fell from nearly $2 \%$ at the beginning of the decade to about $0.7 \%$ during the second quinquennium (table I). This trend reflected a drop in the incidence of planned home deliveries. Because the incidence of unplanned home deliveries showed no trend over the decade the ratio of planned to unplanned births at home changed considerably over the decade. In the early 1970 s nearly five times as many deliveries at home were planned as unplanned; by the end of the decade more deliveries at home were unplanned than planned. (In 1980 there were nearly twice as many unplanned as planned domiciliary births.) About four out of five of the women who delivered at home without planning to do so had intended to deliver in hospital; the remainder had not received any antenatal care and had made no plans for delivery.

The 307 mothers whose deliveries at home had been planned contrasted strikingly with the 129 who had intended to deliver in hospital and even more strikingly with the 30 mothers who had not made any plans for delivery (table II). Compared with the women who gave birth at home as planned, the 30 mothers who had made no plans for delivery were nearly three times as likely to be from social classes IV and V, more than 10 times as likely to be single, and about 20 times more likely to be teenagers and having their first baby.

TABLE II-Characteristics of women delivering at home and of all women resident in Cardiff, Barry, and Penarth who delivered during the 1970s

\begin{tabular}{|c|c|c|c|c|}
\hline & \multicolumn{3}{|c|}{ Deliveries at home } & \multirow[b]{2}{*}{$\begin{array}{c}\text { All women in } \\
\text { reference } \\
\text { population } \\
(n=44048)\end{array}$} \\
\hline & $\begin{array}{l}\text { lanned to } \\
\text { cur at home } \\
(n=307)\end{array}$ & $\begin{array}{l}\text { Planned to } \\
\text { occur in } \\
\text { hospital } \\
(n=129)\end{array}$ & $\begin{array}{l}\text { Completely } \\
\text { unplanned } \\
(\mathrm{n}=30)\end{array}$ & \\
\hline \multirow{3}{*}{$\begin{array}{l}\text { No }(\%) \text { aged }<20 \text { years } \\
\text { No }(\%) \text { nulliparous } \\
\text { No }(\%) \text { in social } \\
\text { classes IV and V } \\
\text { No }(\%) \text { single, } \\
\text { separated, or } \\
\text { divorced }\end{array}$} & $\begin{array}{l}9(2.9) \\
9(2.9)\end{array}$ & $\begin{array}{l}21(16 \cdot 3) \\
17(13 \cdot 2)\end{array}$ & $\begin{array}{l}15(50 \cdot 0) \\
20(66 \cdot 6)\end{array}$ & $\begin{array}{r}6281(14 \cdot 3) \\
18178(41 \cdot 3)\end{array}$ \\
\hline & $63(20.5)$ & $46(35 \cdot 6)$ & $17(56 \cdot 6)$ & $10224(23 \cdot 2)$ \\
\hline & $17(5 \cdot 5)$ & $22(17 \cdot 1)$ & $22(73 \cdot 3)$ & $4713(10 \cdot 7)$ \\
\hline
\end{tabular}

All those mothers whose deliveries at home were planned had received some antenatal care. Indeed, the intensity of care for these women at low risk was greater than average : $215(70.0 \%)$ had made 10 or more antenatal visits compared with only $20002(45 \cdot 4 \%)$ of the reference population. Only $27(20.9 \%)$ of the women who had intended to deliver in hospital but had actually delivered at home were seen on

TABLE I-Trends in incidence of planned and unplanned deliveries at home among women resident in Cardiff, Barry, and Penarth

\begin{tabular}{|c|c|c|c|c|c|c|c|c|c|c|c|c|}
\hline & \multicolumn{11}{|c|}{ Deliveries at home } & \multirow{3}{*}{$\begin{array}{c}\text { Total } \\
\text { deliveries }\end{array}$} \\
\hline & \multicolumn{3}{|c|}{ Planned to take place at home } & \multicolumn{3}{|c|}{ Planned to take place in hospital } & \multicolumn{3}{|c|}{ Completely unplanned } & \multicolumn{2}{|r|}{ All } & \\
\hline & No & $\begin{array}{c}\text { No of home } \\
\text { deliveries }\end{array}$ & $\begin{array}{l}\% \text { of total } \\
\text { deliveries }\end{array}$ & No & $\begin{array}{l}\text { \% of home } \\
\text { deliveries }\end{array}$ & $\begin{array}{l}\% \text { of total } \\
\text { deliveries }\end{array}$ & No & $\begin{array}{l}\% \text { of home } \\
\text { deliveries }\end{array}$ & $\begin{array}{l}\% \text { of total } \\
\text { deliveries }\end{array}$ & No & $\begin{array}{l}\% \text { of total } \\
\text { deliveries }\end{array}$ & \\
\hline $\begin{array}{l}1970-1 \\
1972-3 \\
1974-5 \\
1976-7 \\
1978-9\end{array}$ & $\begin{array}{r}161 \\
62 \\
29 \\
33 \\
22\end{array}$ & $\begin{array}{l}83.0 \\
59.0 \\
55.8 \\
51.6 \\
43.1\end{array}$ & $\begin{array}{l}1.63 \\
0.67 \\
0.34 \\
0.41 \\
0.26\end{array}$ & $\begin{array}{l}23 \\
35 \\
22 \\
26 \\
23\end{array}$ & $\begin{array}{l}11 \cdot 9 \\
33 \cdot 3 \\
42 \cdot 3 \\
40 \cdot 6 \\
45 \cdot 1\end{array}$ & $\begin{array}{l}0.23 \\
0.38 \\
0.26 \\
0.33 \\
0.27\end{array}$ & $\begin{array}{r}10 \\
8 \\
1 \\
5 \\
6\end{array}$ & $\begin{array}{r}5.2 \\
7.6 \\
1.9 \\
7.8 \\
11.8\end{array}$ & $\begin{array}{l}0.10 \\
0.09 \\
0.01 \\
0.06 \\
0.07\end{array}$ & $\begin{array}{r}194 \\
105 \\
52 \\
64 \\
51\end{array}$ & $\begin{array}{l}1.97 \\
1.13 \\
0.61 \\
0.80 \\
0.60\end{array}$ & $\begin{array}{l}9866 \\
9265 \\
8500 \\
7955 \\
8462\end{array}$ \\
\hline
\end{tabular}


more than nine occasions during pregnancy, but this was because 19 $(14.7 \%)$ of the deliveries in this group were preterm compared with only four $(1 \cdot 3 \%)$ of the planned home deliveries.

Either a doctor or a midwife, or both, was present at nearly all (297 $(96.7 \%)$ ) of the planned deliveries at home. By contrast, of the women who had intended to deliver in hospital and those who had not made any arrangements for delivery, only $26(20.1 \%)$ and four $(13.3 \%)$ respectively had a professional attendant present at their deliveries. This was probably because the first stage of labour was stated to have lasted less than two hours or to have been "of short duration" in $75\left(58.4^{\circ}\right)$ of those who had planned to deliver in hospital, in all of those who had had no antenatal care and for whom information was available, but in only $49\left(16.0^{\circ}\right)$ of those who had planned to deliver at home.

Table III summarises the outcome in the babies born at home. Of the 307 babies whose delivery at home had been planned, two died. Both deaths occurred before the onset of labour. One was an unexplained stillbirth of a macerated fetus; the other was associated with rhesus isoimmunisation. All 305 liveborn babies in this group survived the neonatal period, although a neonatal death ascribed to asphyxia occurred in a baby whose mother was transferred to hospital during labour because of fetal distress. Ten $(3.3 \%)$ of the babies born at home as planned were of low birth weight, but the only appreciable morbidity was the development of respiratory distress in two. Respiratory distress also developed in a baby who had been delivered by caesarean section after transfer to hospital during labour because of an intrapartum haemorrhage.

The outcome in babies born to mothers whose deliveries at home had not been planned was very different. Of the 129 babies born to mothers who had intended to deliver in hospital, one normally formed fetus weighing less than $1000 \mathrm{~g}$ died before labour and another two stillborn babies died during delivery, one from trauma, the other (weighing $1500 \mathrm{~g}$ ) from a prolapsed cord. Four neonatal deaths occurred in this group, all of which resulted from complications of immaturity in babies weighing less than $1500 \mathrm{~g}$ at birth. Of the 30 babies born to mothers who had received no antenatal care, six died. There were two intrapartum deaths ascribed to asphyxia, three neonatal deaths from complications of immaturity in babies weighing less than $1500 \mathrm{~g}$ at birth, and one neonatal death in a baby weighing $3500 \mathrm{~g}$ who sustained a fractured skull and died of a subdural haematoma.

This high mortality among babies whose delivery at home had not been planned was reflected in the incidence of serious morbidity. Table III shows the striking difference in the patterns of mortality and morbidity among those babies whose deliveries at home had not been planned compared with those whose deliveries at home had been planned and among the babies in the reference population.

\section{Discussion}

Our analysis shows the heterogeneity of women delivering at home; they may be divided into at least three groups, between which the characteristics of the mothers, the maternity care they receive, and the risk of adverse perinatal outcome contrast strikingly. As the overall incidence of births at home has fallen high risk, unplanned, and unsupervised deliveries have come to predominate. Consequently, by 1977 perinatal mortality among babies delivered at home had risen to quite high levels in England and Wales.

In the relatively small sample studied here the incidence of death among babies whose delivery at home had not been planned was over 10 times that among babies whose delivery at home had been planned. A relative risk of this order has recently been confirmed in a study of all deliveries at home in England and Wales in 1979. (Paper presented by Campbell et al at the 23rd Congress of Obstetrics and Gynaecology, Birmingham, 13 July 1983). Similar but even more striking differences have been reported in the United States. ${ }^{10}$

Our findings have one obvious practical implication. If the proportion of unplanned deliveries at home in our population is representative then roughly 2000 such births must occur every year in England and Wales. This estimate agrees with that made previously by $\mathrm{Tew}^{7}$ and was subsequently shown to be broadly correct for 1979 by the national survey of births at home conducted by Campbell et al (paper presented at 23rd Congress of Obstetrics and Gynaecology). Many of the mothers concerned are teenagers and likely to be frightened both by their pregnancies and by some aspects of the available maternity services. ${ }^{11} 12$ Others, despite good antenatal care and appropriate plans for delivery, go into labour unexpectedly and deliver rapidly thereafter. Clearly the maternity services must find ways of meeting the various needs of these women. Among other things, the concept of the flying squad should not be abandoned just because the proportion of deliveries at home is now so low.

Our findings also prompted us to consider the relative merits of the various methodologies that have been used to analyse risks associated with place of delivery. The complex processes of selection that lead particular women to deliver in particular locations and the resulting heterogeneity of women delivering at home and in hospital must obviously be taken into account in any attempt to obtain unbiased estimates of the risk of perinatal problems directly attributable to alternative places of delivery. To overcome the considerable biases in selection that plague the interpretation of observational data a randomised trial should be mounted; as we have noted previously, ${ }^{13}$ however, it is unlikely ever to be possible to mount a trial of sufficient statistical power to address the issue of perinatal mortality among women at low risk of perinatal loss who would be eligible for such a study.

Broadly speaking, analyses of observational data have adopted one of two approaches in attempts to control for selection biases. The risks of perinatal death associated with the actual place of delivery have been adjusted statistically using information about either mothers ${ }^{14}$ or infants. ${ }^{15}$ Alternatively, data on the risk factors of pregnant women have been used to define a study population with a relatively homogeneous (usually low) predicted risk of perinatal death; this cohort has then been divided into further cohorts defined by the intended place of delivery (as stated at some point during pregnancy). ${ }^{16}$ Whichever of these two broad approaches is used, perinatal deaths that are unlikely to have been influenced by the place of delivery (for example, deaths due to malformations) may or may not have been excluded from the analysis.

The principal proponent of analyses based on groups defined by actual place of delivery is Tew. ' She began her work by observing, correctly, that no analysis of perinatal mortality conducted so far supports the argument that all mothers should give birth in hospital. From her own analyses, however, of data

TABLE III-Mortality and morbidity among babies born at home and amiong all babies delivered in the 1970 s to women resident in Cardiff, Barry, and Penarth. Figures are number of cases, with incidence/1000 births in parentheses

Deliveries at home

\begin{tabular}{|c|c|c|c|c|c|}
\hline & \multicolumn{4}{|c|}{ Deliveries at home } & \multirow[b]{3}{*}{$\begin{array}{c}\text { All births in } \\
\text { reference } \\
\text { population } \\
(\mathrm{n}=\mathbf{4 4 5 2 1 )}\end{array}$} \\
\hline & \multicolumn{2}{|c|}{ Planned to take place at home } & \multirow[b]{2}{*}{$\begin{array}{c}\text { Planned to take place in } \\
\text { hospital } \\
(n=129)\end{array}$} & \multirow[b]{2}{*}{$\begin{array}{l}\text { Completely unplanned } \\
\qquad(\mathrm{n}=30)\end{array}$} & \\
\hline & $\begin{array}{l}\text { Not including transfers to } \\
\text { hospital during labour } \\
(\mathrm{n}=307)\end{array}$ & $\begin{array}{l}\text { Including transfers to } \\
\text { hospital during labour } \\
(\mathrm{n}=315)\end{array}$ & & & \\
\hline $\begin{array}{l}\text { Stillbirths } \\
\text { Neonatal deaths } \\
\text { Live births }<-2501 \mathrm{~g}\end{array}$ & $\begin{array}{c}2(6.5) \\
10(32.6)\end{array}$ & $\begin{array}{c}2(6 \cdot 3) \\
1(3 \cdot 2) \\
11(34 \cdot 9)\end{array}$ & $\begin{array}{c}3(23 \cdot 2) \\
4(31 \cdot 0) \\
25(193 \cdot 8)\end{array}$ & $\begin{array}{l}2(66 \cdot 7) \\
4(133 \cdot 3) \\
7(233 \cdot 3)\end{array}$ & $\begin{array}{r}544(12 \cdot 2) \\
476(10 \cdot 7) \\
3483(78 \cdot 2)\end{array}$ \\
\hline $\begin{array}{l}\text { Cases of: } \\
\text { Respiratory distress syndrome } \\
\text { Hypothermia } \\
\text { Cerebral irritation } \\
\text { Pneumonia }\end{array}$ & $2(6 \cdot 5)$ & $3(9.5)$ & $\begin{array}{l}3(23 \cdot 3) \\
19(147 \cdot 3) \\
6(46 \cdot 5) \\
1(7 \cdot 8)\end{array}$ & $\begin{array}{l}4(133 \cdot 3) \\
6(200 \cdot 0) \\
2(66 \cdot 7) \\
1(33 \cdot 3)\end{array}$ & $\begin{array}{c}562(12 \cdot 6) \\
232(5 \cdot 2) \\
1068(24 \cdot 0) \\
66(1 \cdot 5)\end{array}$ \\
\hline
\end{tabular}


derived from the national perinatal surveys of 1958 and 1970 and from registrations of births and stillbirths, she went on to suggest that the risk of perinatal death is actually increased by delivery in hospital because of the surgical and pharmacological interventions practised there.

In assessing the validity of Tew's conclusions two limitations of her analyses should be noted. Firstly, she was unable to exclude from the data available to her those perinatal deaths that were unlikely to have been influenced by the place of delivery; her analyses thus included deaths due to abnormalities incompatible with extrauterine life (such as anencephaly) and intrauterine deaths that occurred before the onset of labour, which account for most stillbirths. Consequently, a fetal death (due to malformation or any other cause) occurring during pregnancy in a woman booked to deliver at home but then referred to hospital for induction of labour would have been attributed by Tew to the actual place of delivery-that is, the hospital. Secondly, even if the biases resulting from such obvious processes of selection were eliminated by exclusion of such deaths from her analyses, however, we could not share Tew's confidence that statistical adjustment using the descriptive variables available to her successfully controlled for the biases resulting from the less obvious selection processes that lead particular women to deliver in particular places. Good evidence exists that analyses based on this approach can be seriously misleading, even when considerable quantities of descriptive data are available for statistical adjustment. ${ }^{17}$

Quite apart from the difficulties in estimating the risk attributable to place of delivery per se in analyses based on groups defined by actual place of delivery (regardless of intentions), we would question the relevance of such analyses in practice. In our view analyses should be based on comparisons that reflect the actual options open to individual women. These options are either that they should plan to deliver at home in the knowledge that they might need to change these plans if complications developed during pregnancy or labour; or, alternatively, that they should plan to deliver in hospital (whether in a specialist or a general practitioner unit) in the knowledge that they might unexpectedly deliver at home (as did $129(0.3 \%)$ women in our series). In addition to their relevance to the choices that exist in real life, analyses based on comparisons between groups defined by planned place of delivery, if conducted within relatively homogeneous study populations, ${ }^{16} 18$ seem less likely to be subject to the biases in selection that undoubtedly confound comparisons based on groups defined by actual place of delivery. This judgment must remain a matter of opinion until it is possible to compare the estimates of risk obtained using either of these two alternative approaches with estimates derived from unbiased comparisons made within a randomised trial.

If analyses are based on groups defined by intended place of delivery the way in which individual cases are categorised will depend on the extent to which antenatal care varies between the groups under comparison. If similar antenatal care is provided for all women cases should probably be categorised on the basis of the plans for delivery that existed immediately before the onset of labour. In these circumstances deaths that occur before labour (as well as those due to malformations) should be excluded. If, however, substantial differences exist in antenatal care between groups defined by planned place of delivery, and if these differences are likely to affect perinatal outcome, the groups should be defined by plans stated earlier in pregnancy. For example, had the woman in our series whose baby died from rhesus isoimmunisation been booked for delivery in hospital rather than at home her baby's problem might have been recognised and acted on more effectively. On the other hand, antenatal care conducted in hospital clinics when delivery in hospital is expected may lead to unnecessary intervention and also increase the risk of adverse perinatal outcome. ${ }^{19}$ If current recommendations for the adoption of a standard maternity information system are accepted and implemented by regional health authorities $^{20} 21$ analyses could be conducted on samples large enough to give better estimates of the risks of adverse perinatal outcome attributable to planned place of delivery.

In the light of past experience, ${ }^{22}$ however, the planning of maternity services at either national or local level is highly unlikely to be influenced by such estimates, whatever they show. Estimates derived from large population aggregates might not be accepted as relevant either by individual women making choices between alternative places of delivery, ${ }^{23}$ or by professionals planning and providing maternity services. We think that judgments about the merits and demerits of delivery in different places will probably take into account not just the class of the planned place of delivery but also the perceived quality and quantity of resources, human and otherwise, available in each particular locality.

We thank all those who have contributed in various ways to the Cardiff Births Survey; colleagues who have made helpful criticisms of earlier drafts of this report, especially Marjorie Tew; and Lesley Mierh and Lynn Gedrych for typing the manuscript. IC is supported by a grant from the Department of Health and Social Security. JFM was supported by grants from the Jane Hodge Foundation and South Glamorgan Area Health Authority.

\section{References}

${ }^{1}$ Davies IMM. Perinatal and infant deaths: social and biological factors. Population Trends 1980;19:19-21.

2 House of Commons Social Services Committee. Perinatal and neonatal mortality 1979-80, Second report. London: HMSO, 1980:26-7.

${ }^{3}$ Department of Health and Social Security. Reply to the second report from the social services committee on perinatal and neonatal mortality. London: HMSO, 1980:19. (Cimnd 8084)

4 Bull MJV. Perinatal mortality figures distorted. Pulse 1980 May 3:45.

5 Tew M. Facts, not assertions of belief. Health and Social Service fournal 1980;90:1194-7.

${ }^{6}$ Garrow DH. Childbirth at home. The Times 1981 Feb 2:15.

7 Tew M. Effect of scientific obstetrics on perinatal mortality. Health and Social Service fournal 1981;91:444-6.

${ }^{8}$ Campbell R, Davies IMM, Macfarlane A. Perinatal mortality and place of delivery. Population Trends 1982;28:9-12.

${ }^{9}$ Andrews J, Davies K, Chalmers I, Campbell $H$. The Cardiff Births Survey: development, perinatal mortality, birthweight and length of gestation. In: Harper PS, Sunderland E, eds. Genetic and population studies in Wales. Cardiff: University of Wales Press (in press).

10 Burnett CA, Jones JA, Rooks J, Chen CH, Tyler CW Jr, Miller CA. Home delivery and neonatal mortality in North Carolina. $\mathcal{F} A M A 1980 ; 244$ : 2741-5.

11 Dott AB, Fort AT. Medical and social factors affecting early teenage pregnancy. Am $\mathcal{F}$ Obstet Gynecol 1976;125:532-6.

12 Parsons W, Perkins E. Why don't women attend for antenatal care? Leverhulme Health Education Project. Occasional Paper No 23. Nottingham: University of Nottingham, 1980.

13 Chalmers I. Implications of the current debate on obstetric practice. In: Kitzinger S, Davis JA, eds. The place of birth. Oxford: Oxford University Press, 1978:44-53.

14 Tew M. The case against hospital deliveries: the statistical evidence. In: Kitzinger S, Davies JA, eds. The place of birth. Oxford: Oxford University Press, 1978:55-6.

15 Ashford JR. Policies for maternity care in England and Wales: too fast and too far. In: Kitzinger S, Davies JA, eds. The place of birth. Oxford: Oxford University Press, 1978:14-44.

16 Fedrick J, Butler NR. Intended place of delivery and perinatal outcome. Br Med f 1978; i:763-5.

17 Coronary Drug Project Research Group. Influence of adherence to treatment and response of cholesterol on mortality in the coronary drug proiect. $N$ Engl f Med $1980 ; 303: 1038-41$.

18 Klein M, Lloyd I, Redman C, Bull M, Turnbull AC. A comparison of low-risk pregnant women booked for delivery in two systems of care: shared care (consultant) and integrated general practice unit. $\mathrm{Br} \mathcal{F}$ Obstet Gynaecol 1983;90:118-28.

19 Chalmers I, Dauncey ME, Jones ERV, Dodge JA, Gray OP. Respiratory distress syndrome in infants of Cardiff residents during 1965-1975. Br Med F 1978; ii:1119-21.

20 Thomson AM, Barron SL. A standard maternity information system. In: Chalmers I, McIlwaine G, eds. Perinatal audit and surveillance. London: Royal College of Obstetricians and Gynaecologists, 1980:79-92.

21 Steering group on health services information. First report to the secretary of state. London: HMSO, 1982.

${ }^{22}$ Black $N$. Tales of the expected: a case study in health services management. Soc Sci Med 1982;16:1801-6.

${ }^{23} \mathrm{Zander}$ LI. The place of confinement-a question of statistics or ethics ? f Med Ethics $1981 ; 7: 125-7$.

(Accepted 31 fanuary 1984) 